\title{
Scout, Snap, and Share: First Impressions of Plant Disease Monitoring Using Social Media
}

Daren S. Mueller, ${ }^{\dagger}$ Adam J. Sisson, and Rachel Kempker, Department of Plant Pathology and Microbiology, Iowa State University, Ames 50011; Scott Isard, Department of Plant Pathology and Environmental Microbiology, Penn State University, University Park 16802; and Conner Raymond, Andrew J. Gennett, William Sheffer, and Carl A. Bradley, Department of Plant Pathology, University of Kentucky Research and Education Center, Princeton 42445

\begin{abstract}
The social media platform Twitter was used to monitor corn and soybean diseases in the United States during 2016 and 2017 as part of a campaign to involve crop scouts, farmers, educators, and agricultural advisors in disease data sharing. The purpose was to explore the feasibility of providing farmers and crop consultants with an easily accessible, user-friendly, no-cost platform for sharing disease observations with rapid information transfer and early warning capabilities. Two Twitter accounts were created, @ soydisease and @ corndisease, as part of an accessible data collection method for later input into the Integrated Pest Information Platform for Extension and Education (iPiPE). Multiple methods were employed to create awareness and recruit users, which included writing articles for extension and popular farm news outlets and directly contacting

potential agribusiness and extension stakeholders. From the creation of the accounts in February 2016 through September 2017, there were 738 followers and 8,668 profile visits for @ soydisease; and 1,149 followers and 17,294 profile visits for @ corndisease,with a variety of contributors including university extension, industry agronomists and service providers, students, a commodity group, and agricultural news. During the 2016 and 2017 growing seasons, use of the Twitter disease-monitoring campaign successfully helped track the movement of southern rust (caused by Puccinia polysora) of corn northward, allowing for advanced notice for scouting efforts. Although this is only an initial attempt, it shows that representatives from across a wide variety of agricultural sectors can contribute to a plant disease monitoring system using a common social media engine.
\end{abstract}

Diseases reduce profit and yield each year in corn and soybean. Mueller et al. (2016) reported estimated yield losses in corn to disease in the United States and Ontario, Canada, of over 155 million metric tons from 2012 to 2015 , valued at over $\$ 27$ billion. Reduction in soybean production due to disease in the same region was estimated to be almost 59 million metric tons from 2010 to 2014, equivalent to nearly $\$ 26$ billion (Allen et al. 2017). On a per hectare basis, these studies estimate that diseases cause economic losses of $\$ 188.59$ and $\$ 149.89$ per hectare in corn and soybean, respectively.

Effective crop disease management during a growing season requires disease identification through field scouting followed by appropriate management action. However, this can be difficult for several reasons: i) problematic diseases vary with year and do not always show up at the same time; ii) some diseases can be confused with other diseases, noninfectious disorders, and even insect injury, causing misidentification; and iii) disease management is only a small part of a farmers' overall operation and is simply one concern out of many. As a result, farmers and crop consultants may devote inadequate time to disease scouting. For these reasons, it is important for extension personnel, agronomists, and crop scouts who make field observations in support of production agriculture to share knowledge gained during field scouting with the greater community of agricultural stakeholders. Not only would more comprehensive and timely information on disease distribution and severity improve

${ }^{\dagger}$ Corresponding author: D. S. Mueller; E-mail: dsmuelle@iastate.edu

Funding: Funding for this project was provided by the United States Department of Agriculture National Institute of Food and Agriculture through the Integrated Pest Information Platform for Extension and Education (iPiPE) Cooperative Agricultural Project (CAP).

Accepted for publication 27 March 2018.

(c) 2018 The American Phytopathological Society the overall productivity and stewardship of our agro-ecosystems, but would also help ensure the safety of our food supply and national security.

One way of accomplishing this is to create online networks where data are freely shared among experts and those making the day-today farming decisions. One such effort is the Integrated Pest Information Platform for Extension and Education (iPiPE; http://www.ipipe. org). This multicrop platform acts as a clearinghouse of pest distribution information as well as expert commentary for a variety of diseases utilizing input from extension professionals across the United States for multiple crops (Isard et al. 2015). iPiPE receives funding through the National Institute of Food and Agriculture, U.S. Department of Agriculture, and is administered by ZedX Inc., a private company. Primary contributors are extension specialists who are responsible for tracking crop pests and disease through a variety of methods, with the goal of protecting crop production in the United States. A previous incarnation of this monitoring effort was similarly known as the Pest Information Platform for Extension and Education (ipmPIPE; http://ipmpipe.org/), which was central to the soybean rust monitoring system (Bradley et al. 2010; Isard et al. 2015; Sikora et al. 2014; VanKirk et al. 2012). Despite the useful layers of functionality these resources employ, including mapping components, there are a few drawbacks with using these systems on a standalone basis for long-term information flow directly to and from stakeholders and extension professionals.

The sustainability of information platforms such as iPiPE and ipmPIPE is an important issue. In general, they are expensive to maintain, requiring support for subject matter experts who enter and interpret observations. For this reason, many such platforms fail once the grant that funded their development and initial few years of operation terminates. Another drawback to these systems is that they may not be easy to use, time efficient, or well known among potential users. To increase the likelihood of stakeholders adopting a pest reporting system, they must be well advertised, readily available, free, and intuitive.

Social media platforms, such as Twitter (San Francisco, CA), are viable alternatives to custom-designed and subsequently high-cost 
reporting systems for reporting crop disease. In the United States, there were 67 million active Twitter users at the end of 2016 (Statista 2017). The use of Twitter may be advantageous for several reasons including: top technology experts are responsible for software creation and maintenance (it is an existing and well supported platform), nearly everyone has access (the platform is available on any smartphone, tablet, or personal computer), Twitter is refined for ease of use (catering to diverse users), desired content providers can be subscribed to (followed), and importantly, Twitter is free to use. Twitter has the potential to enable swift information transfer among stakeholders, for timely discovery of disease issues and rapid dissemination of important scouting and management information. Disease observations compiled through this social media tool can be later input as data into platforms such as the iPiPE system for archiving and mapping purposes.

Thus, the goal of this project was to use Twitter to monitor corn and soybean diseases in the United States during 2016 and 2017 as

\section{Real-time sharing of pest information through Twitter}
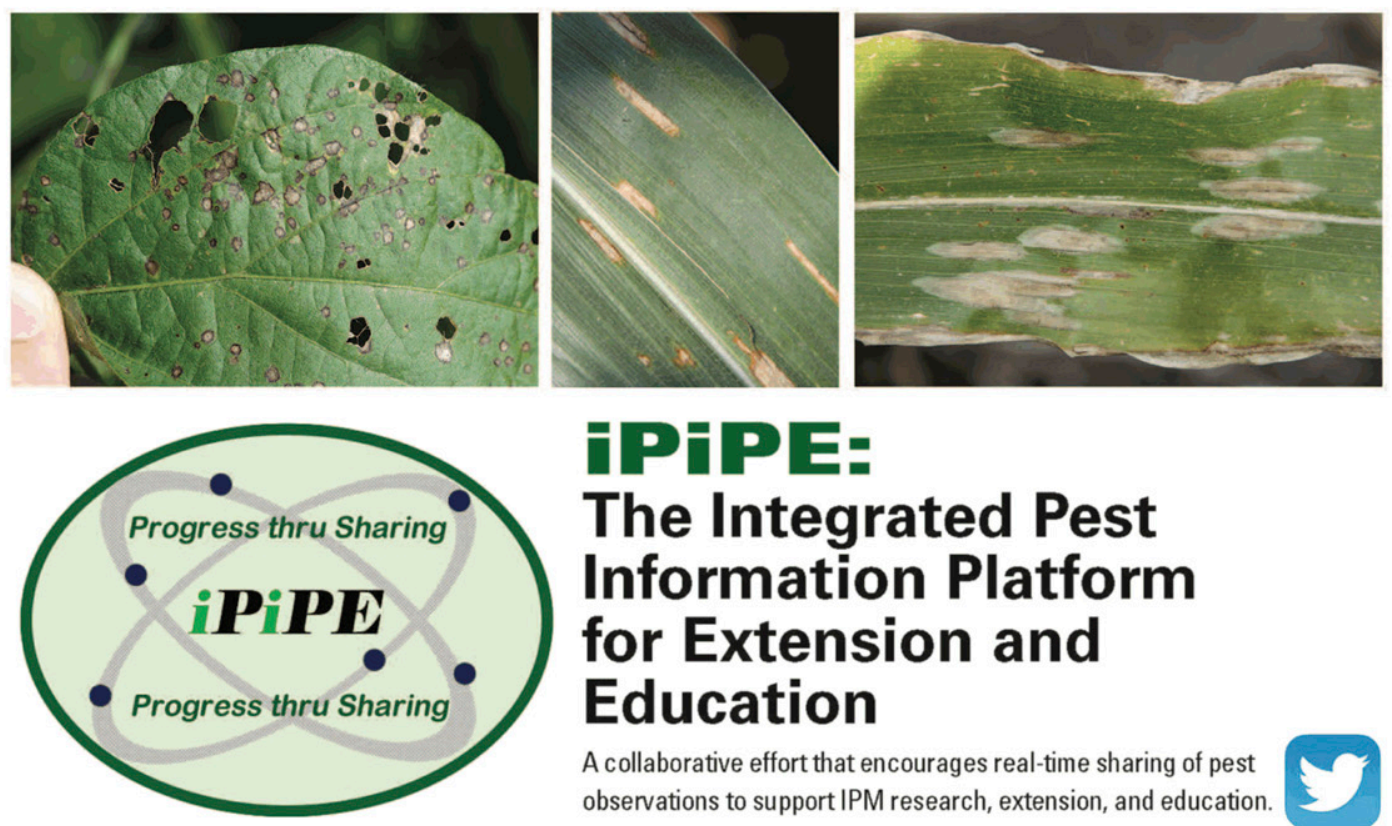

A collaborative effort that encourages real-time sharing of pest observations to support IPM research, extension, and education.

\section{iPiPE: The Integrated Pest Information Platform for Extension and Education}
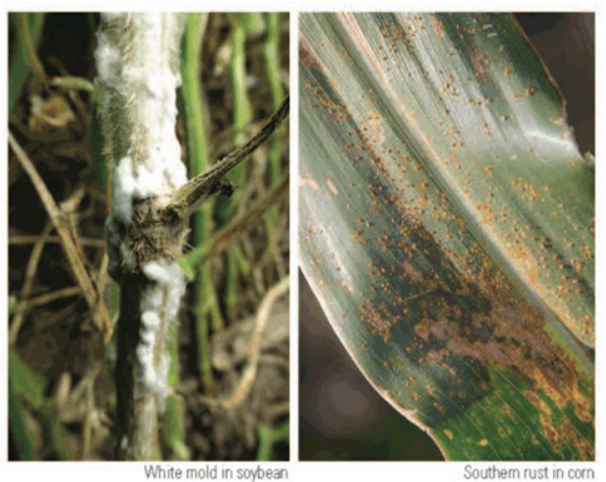

Submit your observations from the field

Just remember: Scout, Snap and Share!

1) Scout: Observe crop disease

2) Snap: Take a good picture (in focus) showing the symptoms

3) Share: Tweet out the disease and include:

our Twitter handles,

- corn disease tweets: @corndisease

- soybean disease tweets: @soydisease

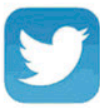

the name of the county and state,

name of the disease,

and the picture.

For example: @soydisease seeing white mold in Rock County WI

\section{Why participate?}

- Learn where diseases are showing up in corn and soybean fields across the U.S.

- Help develop distribution maps of corn and soybean diseases to help guide scouting efforts

- Information will be used by researchers to develop prediction maps for when and where diseases occur

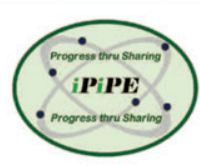

For more information about the iPiPE program, visit ipipe.org.

For more information about the soybean disease and corn disease iPiPE programs, contact:

Dr. Daren Mueller (soybean diseases), dsmuelle@iastate.edu

Dr. Carl Bradley (corn diseases), carl.bradley@uky.edu

Fig. 1. Promotional printing (front and back) used to create awareness of the disease-tracking Twitter campaign through the Integrated Pest Information Platform for Extension and Education (iPiPE). 
part of a campaign involving crop scouts, farmers, educators, and agricultural advisors in disease data sharing. The purpose was to explore the feasibility of providing an early warning system with rapid information transferring capabilities for crop diseases that relies on an easily accessible, user-friendly, and no cost information sharing platform.

\section{Materials and Methods}

Twitter accounts for corn and soybean diseases were created in February 2016 to gather and share disease monitoring data as part of an accessible data collection method for later input into iPiPE. Corn Diseases was assigned a Twitter handle of @ corndisease (https:// twitter.com/corndisease), and Soybean Diseases had a Twitter handle of @ soydisease (https://twitter.com/soydisease). These accounts were managed (including retweeting related posts) by iPiPE student interns at Iowa State University (@soydisease) and the University of Kentucky (@corndisease). When tweeting to these accounts, users were asked to post an image of the disease, the disease name, and the county and state where it was found, and include either@ @soydisease or @ corndisease in the post. The posts became immediately available for stakeholder viewing. These data were then entered into the iPiPE monitoring system for archiving and mapping.

To create awareness and promote participation in the two Twitter campaigns, a variety of methods were used. Online news articles were developed and posted by university extension and agricultural news outlets, and articles were reposted at other online news and blog sites. Direct contact via e-mail and in person promotion to more than 500 people occurred via many different venues. Promotional postcards were also designed and printed to increase awareness (Fig. 1 and https://crops. extension.iastate.edu/files/blog/files/IPM0075.iPiPEpostcard.pdf). To instruct Twitter followers on techniques for capturing quality images, a video demonstrating how to best take images of diseased corn and soybean plants using a mobile device was developed and distributed through YouTube (https://youtu.be/TG4aFVaMpCs).

Tweets occurring at @ corndisease were categorized according to quality and purpose at the completion of the 2017 season. Observations of southern rust, a highly mobile fungal disease of corn, illustrated the monitoring potential of social media. Locations and dates of southern rust observations on Twitter were recorded and mapped throughout both seasons, as were reports via iPiPE. Twitter observations were added to the iPiPE system for archiving and mapping.

Twitter Analytics was used to obtain user data for @ soydisease and @ corndisease including profile visits, followers, tweet impressions, tweets, and mentions. A tweet impression is the number of instances a tweet is delivered to another user in search results or a timeline, while a mention is a tweet that includes the username of another Twitter account.

\section{Results}

User data from February 2016 onward was recorded from the Twitter Analytics page for each account on 22 September 2017. For @ soydisease, there were 8,668 profile visits, 738 followers, 40,755 tweet impressions, 37 tweets, and 269 mentions. For @ corndisease, there were 17,294 profile visits, 1,149 followers, 112,991 tweet impressions, 103 tweets, and 529 mentions.

Quality and purpose of tweets were variable at @ corndisease (Table 1). Primary tweet activity was individual observations of disease, but tweets also included information and outreach about relevant resources and disease data from crop protection specialists. Several disease identification requests were also tweeted each year. The total number of disease observation tweets increased by $68 \%$ from 2016 to 2017, from 62 to 104 tweets, respectively.

In regard to southern rust, there were 43 observations initially reported on Twitter and 113 observations reported through iPiPE in 2016 (Fig. 2). Observations of southern rust reported on Twitter preceded those recorded into the iPiPE system in Georgia, Iowa, Kansas, and Nebraska. In North Carolina and Texas, Twitter observations were the only recorded findings. In 2017, 78 and 280 southern rust observations were reported on Twitter and through iPiPE, respectively (Fig. 3). It is important to note that not all observations reported on Twitter are likely to be real occurrences of the disease. For example, an unconfirmed Twitter observation of southern rust was reported in Iowa in mid-June of 2016, an unlikely time to find a disease that generally occurs later in the season in the Midwest.

\section{Discussion}

The authors believe the campaign was successful at determining the potential for disease monitoring using Twitter, specifically with tracking movement of southern rust of corn, and that in years or regions with emerging disease issues, a corresponding increase in social media communications will occur. For example, when analyzing Twitter communications during a drought beginning in 2012 in Nebraska, Wagler and Cannon (2015) discovered that as the drought grew worse, Twitter communications increased regarding the drought.

There were many advantages observed during the disease monitoring campaign, and when examining the Twitter platform in general. First, the platform is easily accessible using smartphones, tablets, and laptop and desktop computers from any location that receives an internet signal. Secondly, this platform is simple to use, both in terms of software design and in what contributors are required to submit as part of a report. Third, and perhaps one of the most important aspects, is that this platform already exists. No additional funding is required to develop specialized apps or a user interface, and no continuation of funding is necessary to maintain and update software and websites. Additionally, people may be more likely to use this platform, and the familiarity of the platform is widespread among stakeholders, many of whom already have accounts.

Another advantage is that information spread is rapid and immediately available, a fact illustrated in both 2016 and 2017 when southern rust observations were recorded on Twitter prior to being reported by the iPiPE system. This occurred in multiple states. These "boots on the ground" finds can direct extension and other crop health practitioners to the areas where scouting needs to occur for timely disease issues. Information flow using Twitter is also multidirectional, as crop protection specialists provided relevant outreach and information on diseaserelated resources to stakeholders via the same platform where disease observations were recorded.

There are, however, disadvantages to using Twitter to track and record disease data. There is, at this time, no automated ability to compile multiple reports without a specialist sifting through tweets and producing the reportable output desired, as opposed to the mapping system available with other monitoring systems. Related, there are no specialized functions available to Twitter users specifying the exact

Table 1. Category (quality and/or purpose) of tweets posted to @ corndisease in 2016 and 2017 for tracking diseases of corn

\begin{tabular}{lcr}
\hline & \multicolumn{2}{c}{ Number of tweets } \\
\cline { 2 - 3 } Tweet category & $\mathbf{2 0 1 6}$ & $\mathbf{2 0 1 7}$ \\
\hline $\begin{array}{l}\text { Complete: All data elements required to track } \\
\text { disease present }\end{array}$ & 40 & 82 \\
$\begin{array}{l}\text { Incomplete: One or more data elements } \\
\text { required to track disease missing }\end{array}$ & 17 & 15 \\
$\begin{array}{l}\text { Image quality poor or incorrect } \\
\text { Outreach }^{\mathrm{c}}\end{array}$ & 5 & 7 \\
$\begin{array}{l}\text { Promotional } \\
\text { Requests for disease identification }\end{array}$ & 12 & 28 \\
$\begin{array}{l}\text { Southern rust (Puccinia polysora) } \\
\text { progression }^{\mathrm{e}}\end{array}$ & 17 & 11 \\
\hline
\end{tabular}

a Tweets are original posts that specifically include @ corndisease. Information on retweets was not recorded.

${ }^{b}$ Elements required to track disease include disease name, quality image, and location (state and county).

${ }^{c}$ Outreach tweets provide information on topics such as crop scouting tips or further disease information.

d Promotional tweets provide information on crop scouting resources such as publications, the disease-tracking Twitter campaign, and the Integrated Pest Information Platform for Extension and Education (iPiPE).

e Progression of southern rust tweets provide information about overall distribution of disease, rather than individual observations. In 2017, southern rust progression tweets included links to distribution maps at iPiPE. 
type of information needed for a proper posting, or other specialized functions.

Another drawback is the posting of false positives. This was observed in 2016 when an early report of southern rust surfaced in Iowa through Twitter that was unlikely to be correct. This may serve to confuse other users, and could lead to initiation of unnecessary management. However, plant disease experts can monitor and respond to obvious false positives that are posted by examining the image

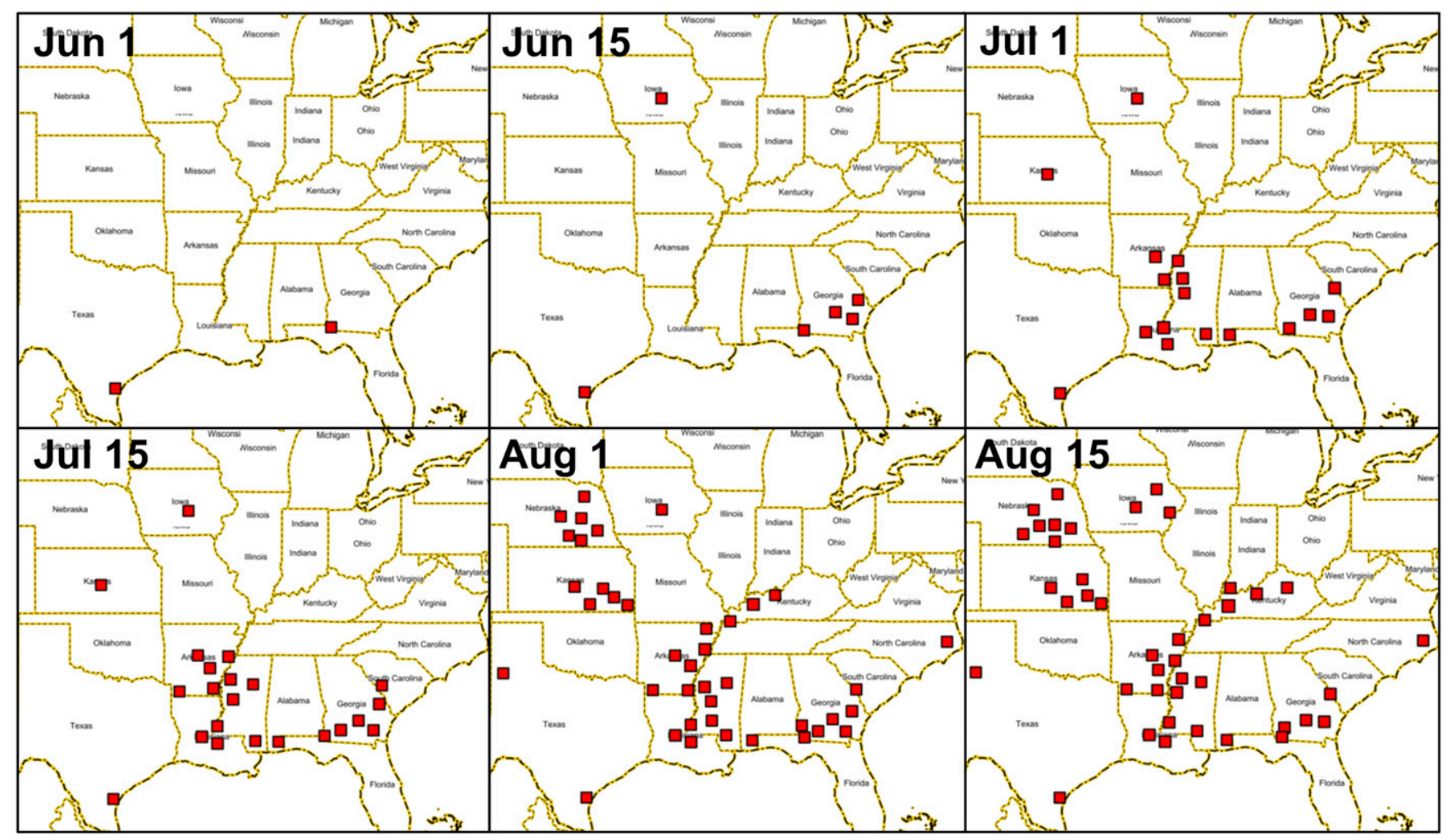

Fig. 2. Sequence of southern rust (caused by Puccinia polysora) of corn observations over time as reported through Twitter and iPiPE in 2016 from 1 June until 15 August.

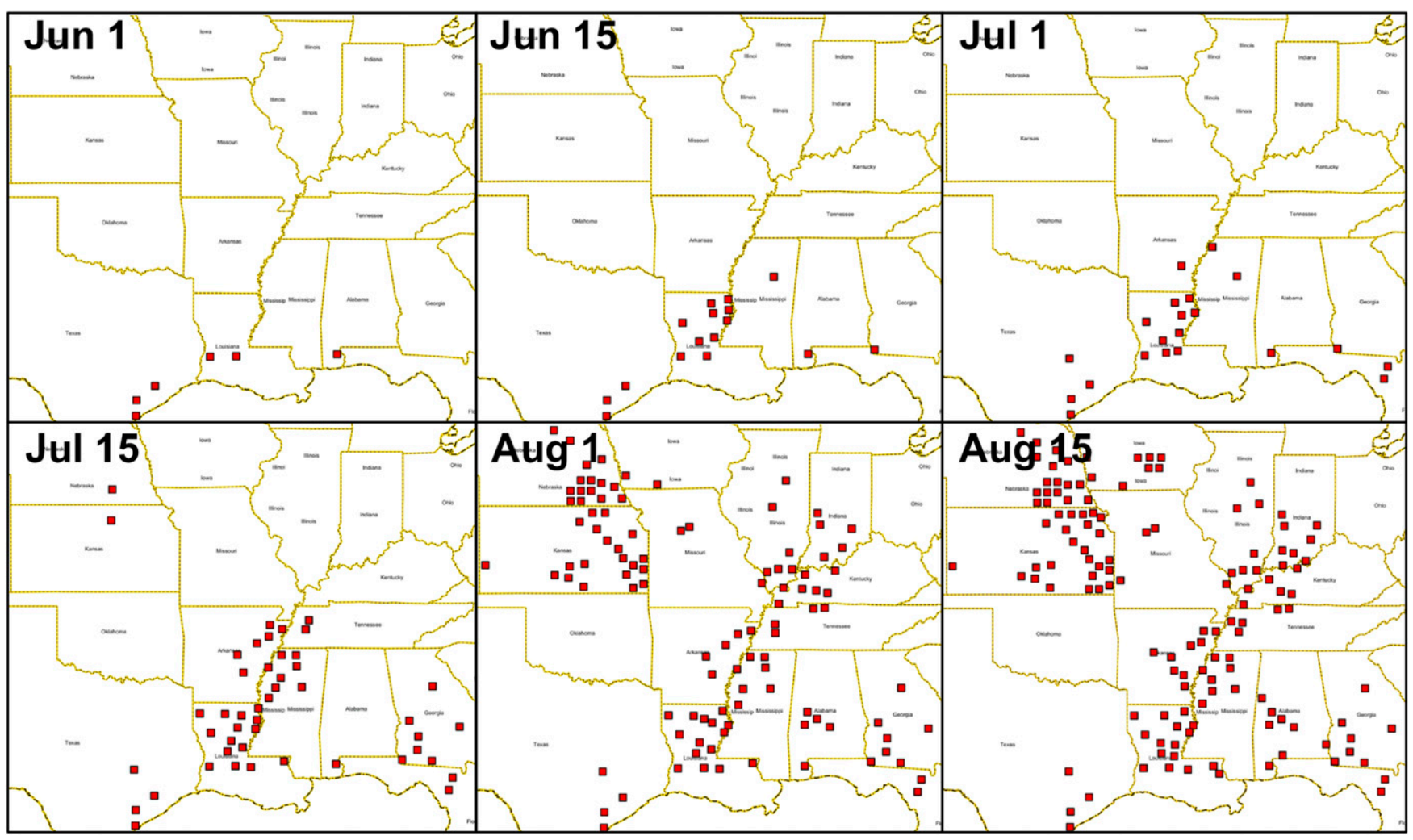

Fig. 3. Sequence of southern rust (caused by Puccinia polysora) of corn observations over time as reported through Twitter and iPiPE in 2017 from 1 June until 15 August. 
included with diagnostic tweet and considering pathogen biology. This creates an unofficial "quality control" that works to prevent misinformation.

Amplification of risk perception among social media users may also be important to consider (Rutsaert et al. 2013). Posting disease occurrence information to Twitter without providing appropriate context may serve to increase the perceived risk of a disease, and cause initiation of unnecessary management. For example, a disease susceptible cultivar growing in an inoculum-rich environment may exhibit severe disease symptoms in an image posted to Twitter. This may cause alarm among nearby land managers, whereas actual risk may be low in neighboring fields due to cultivar selection and differing farm management strategies. Posts showing severe disease should only help to inform field scouting efforts, rather than management action.

There is also the important aspect of privacy, which encompasses several issues including the reluctance of Twitter users with existing accounts to mix work with personal information; agribusiness concerns with what employees are posting and how this represents their company; agribusiness clientele may not feel comfortable with information from their field being shared with the public, even though it is only identified to the county level; and sharing pest information may not be perceived as being beneficial to agribusinesses or their clientele (Magarey et al. 2009). It may also be hard for farmers to reveal that they have found a particular disease or production issue in one of their fields, as this may impact how others view their ability to farm.

Conversely, Twitter use may also present an opportunity to dissolve barriers to information sharing in two ways. First, many users have their own personal account, which is not affiliated with or endorsed by their employer. This may allow disease reporters to have a degree of freedom and increase willingness to share finds with these personal accounts that are not agribusiness endorsed. Secondly, sharing disease finds may be advantageous to those seeking increased visibility for their business through social media, serving to create new contacts and increase the appearance of expertise and relevance with current and potential clientele.

We observed that information posters did not always follow posting instructions. We asked that an image of the disease, a disease name, and county/state were to be posted as part of a Tweet. Sometimes, the location would be left out of the Tweet, reducing the usefulness of the report. This tells us that contributing data to more complex monitoring systems could prove to be a difficult task, in particular for the general public who cannot be expected to invest the amount of time required to gain proficiency in posting to these more complex systems. Over the course of time, however, extension specialists who contributed information using the Twitter handles improved in their reporting skills. Thus, as reporting disease via Twitter becomes normalized, we expect reporting ability among core contributors to increase. In fact, the percentage of incomplete or quality poor/incorrect disease observation tweets from contributors fell from $22 \%$ in 2016 to $12.7 \%$ in 2017 , even though overall tweet activity increased in 2017.

The medical community has recently examined the use of social media for surveillance and outbreak management of human illness by health practitioners (Charles-Smith et al. 2015). Other crop disease monitoring efforts are also underway using Twitter. Examples include reporting stripe rust of wheat using the hashtag \#striperust and crop disease monitoring in the United Kingdom with@CropMonitor.

Wagler and Cannon (2015) also suggest that social media can be used "... to disseminate timely and relevant information related to important public issues, while also monitoring and participating in surrounding discussions." The latter part of this statement is another strong aspect of using Twitter as a vehicle for communication - it allows the crop health practitioners to be party to the "common discussions" about a topic. Engaging in multidirectional communication, crop health practitioners can work to dispel misinformation, determine need for further education opportunities, and gain familiarity with their audience.
After considering the advantages and disadvantages of the Twitter platform for disease monitoring, the surveillance and outbreak management of crop diseases by extension personnel and industry agronomists seems to be the strongest aspect of the monitoring system, providing quick and efficient access and distribution of important information to and from farm manager stakeholders. An early discovery of a crop disease outbreak may result in more effective management over many acres, as crop diseases are often best treated before becoming established. This can mean increased yields and improved economic returns for farmers.

Overall, we discovered that Twitter has both positive and negative aspects, not unlike any system used for monitoring plant disease. Also, this is a platform that can be useful for any type of crop issue monitoring, from insects to invasive or resistant weeds. It has an appeal to the citizen scientist, providing a way for them to contribute for the greater good. Reports supply the extension specialist or industry agronomist with information that will help others and produce a community-wide benefit for corn and soybean growers and those that support them.

\section{Acknowledgments}

Thank you to the farmers, students, agribusinesses, and extension personnel who contributed information during this project.

\section{Literature Cited}

Allen, T. W., Bradley, C. A., Sisson, A. J., Byamukama, E., Chilvers, M. I., Coker, C. M., Collins, A. A., Damicone, J. P., Dorrance, A. E., Dufault, N. S., Esker, P. D., Faske, T. R., Giesler, L. J., Grybauskas, A. P., Hershman, D. E., Hollier, C. A., Isakeit, T., Jardine, D. J., Kemerait, R. C., Kleczewski, N. M., Koenning, S. R., Kurle, J. E., Malvick, D. K., Markell, S. G., Mehl, H. L., Mueller, D. S., Mueller, J. D., Mulrooney, R. P., Nelson, B. D. Newman, M. A., Osborne, L., Overstreet, C., Padgett, G. B., Phipps, P. M., Price, P. P., Sikora, E. J., Smith, D. L., Spurlock, T. N., Tande, C. A., Tenuta, A. U., Wise, K. A., Wrather, J. A., and Kelly, H. 2017. Soybean yield loss estimates due to diseases in the United States and Ontario, Canada from 2010 to 2014. Plant Health Prog. doi.org/10.1094/PHP-RS16-0066

Bradley, C. A., Allen, T. W., Dorrance, A. E., Dunphy, E. J., Giesler, L. J., Hershman, D. E., Hollier, C. A., Horn, V., and Wrather, J. A. 2010. Evaluation of the soybean rust pest information platform for extension and education (PIPE) public website's impact on certified crop advisers. Plant Health Prog. doi.org/10.1094/PHP-2010-0701-01-RS

Charles-Smith, L. E., Reynolds, T. L., Cameron, M. A., Conway, M., Lau, E. H Y., Olsen, J. M., Pavlin, J. A., Shigematsu, M., Streichert, L. C., Suda, K. J., and Corley, C. D. 2015. Using social media for actionable disease surveillance and outbreak management: a systematic literature review. PLoS ONE 10:e0139701.

Isard, S. A., Russo, J. M., Magarey, R. D., Golod, J. and VanKirk, J. R. 2015 Integrated Pest Information Platform for Extension and Education (iPiPE): Progress through sharing. J. Integr. Pest Manag. 6:15.

Magarey, R. D., Colunga-Garcia, M., and Fieselmann, D. A. 2009. Plant biosecurity in the United States: roles, responsibilities, and information needs. Bioscience 59:875-884.

Mueller, D. S., Wise, K. A., Sisson, A. J., Allen, T. W., Bergstrom, G. C., Bosley, D. B., Bradley, C. A., Broders, K. D., Byamukama, E., Chilvers, M. I., Collins, A., Faske, T. R., Friskop, A. J., Heiniger, R. W., Hollier, C. A., Hooker, D. C., Isakeit, T., Jackson-Ziems, T. A., Jardine, D. J., Kelly, H. M., Kinzer, K., Koenning, S. R., Malvick, D. K., McMullen, M., Meyer, R. F., Paul, P. A., Robertson, A. E., Roth, G. W., Smith, D. L. Tande, C. A., Tenuta, A. U., Vincelli, P., and Warner, F. 2016. Corn yield loss estimates due to diseases in the United States and Ontario, Canada from 2012 to 2015. Plant Heath Prog. doi.org/10.1094/PHP-RS16-0030

Rutsaert, P., Regan, A., Pieniak, Z., McConnon, A., Moss, A., Wall, P., and Verbeke, W. 2013. The use of social media in food risk and benefit communication. Trends Food Sci. Technol. 30:84-91.

Sikora, E. J., Allen, T. W., Wise, K. A., Baniecki, J., Bergstrom, G., Bradley, C., Brown-Rytlewski, D., Chilvers, M., Coker, C., Damicone, J., DeWolf, E., Dorrance, A., Dufault, N., Esker, P., Faske, T., Giesler, L., Goldberg, N., Golod, J., Gomex, I. R. G., Grau, C., Grybauskus, A., Franc, G., Hammerschmidt, R., Hartman, G., Henn, A., Hershman, D., Hollier, C., Isakeit, T., Isard, S., Jacobson, B., Jardine, D., Kemerait, B., Koenning, S., Langham, M., Malvick, D., Markell, S., Marois, J., Monfort, S., Mueller, D., Mueller, J., Mulrooney, B., Newman, M., Osborne, L., Padgett, G. B., Ruden, B., Rupe, J., Schneider, R., Schwartz, H., Shaner, G., Singh, S., Stromberg, E., Sweets, L., Tenuta, A., Trippett, C., Vaiciunas, S., Yang, 
X. B., Young-Kelly, H., and Zidek, J. 2014. A coordinated effort to manage soybean rust in North America: a success story in soybean disease monitoring. Plant Dis. 98:864-875.

Statista. 2017. Number of monthly active Twitter users in the United States from the 1 st quarter 2010 to 4 th quarter 2016 (in millions). https://www.statista.com/ statistics/274564/monthly-active-twitter-users-in-the-united-states/. Accessed 22 March 2017.
VanKirk, J. R., Isard, S. A., Cardwell, K. F. and Draper, M. A. 2012. The ipmPIPE overview, lessons, opportunities, and challenges. J. Integr. Pest Manag. 3:C1-C7. Wagler, A., and Cannon, K. J. 2015. Exploring ways social media data inform public issues communication: an analysis of Twitter conversation during the 2012-2013 drought in Nebraska. Paper 82, Faculty Publications, Agricultural Leadership, Education \& Communication Department, University of Nebraska, Lincoln. https://digitalcommons.unl.edu/aglecfacpub/82/ 